\title{
hornos verticales*
}

\author{
JULIAN REZOLA IZAGUIRRE \\ de Cementos Rezola, S. A.
}

Al hablar de Ios hornos verticales, vaya por delante que no se trata de establecer ningún parangón entre este tipo de hornos y los rotativos. Simplemente, se trata de comentar ligeramente la experiencia que podamos tener sobre los verticales, y dar paso a que otros compañeros nos hablen de la suya.

La nuestra nos dice que el horno vertical, en el que se han reunido las ventajas que la práctica ha señalado de unos años a esta parte, para mejorar algunos puntos débiles de los muchos del sistema, y a cuyo horno se hace llegar un material crudo debidamente homogeneizado y de finura elevada, nos proporciona un clínker muy aceptable, de inestimables aplicaciones en muchos casos particulares, y conseguido en una instalación económica y en muy buenas condiciones de rendimiento.

El horno vertical puede, por lo tanto, ser recomendado a veces, si no como solución brillante, sí como solución práctica, por ejemplo en los casos de instalaciones de coste reducido, que ocupan poco espacio y son de fácll montaje.

Si se trata de obtener producclones modestas, o cuando el abastecimiento de ciertos carbones es dificil y, sobre todo, cuando se cuenta con materias primas adecuadas, la presencia del horno vertical puede ser una solución rentable.

Hemos aludido a los puntos débiles del sistema. El primero no tué propiamente atributble al horno en si, sino más bien a los defectuosos medios existentes hace cincuenta años para preparar los crudos, que resultaban muy deflcientes en cuanto a flnura, dejando grandes residuos sobre los tamices y slendo muy defectuosa, o nula, la homogeneización de los mismos. Por eso se buscaban materias de composición parecida a la de la dosificación final del crudo (margas). Las mezclas a base de composiciones extremas daban origen a grandes dificultades.

Pero, aparte de la defectuosa preparación de los crudos, el sistema tenia otros inconvenientes, lo mismo en la dosiflcaclón de materias primas y combustibIe, que en los aglomerados para la alimentación, en la combustión y en la descarga. Todo el conjunto llevaba consigo una marcha dificil, y un material de muy desigual clínkerdzación y muy baja calldad.

El pasar revista a la evolución del horno vertical en estos años, hasta el presente, no nos parece descripción adecuada en este momento. Todos la conocen. Lo clerto es que hemos llegado al horno vertical actual, que admite materias primas de composición extrema, que se pueden moler finamente y homogeneizar a la perfección; al horno que admite grandes presiones de alre $y$, como consecuencia, mayor velocidad de descarga, menor permanencia del clínker en él, y mayores producctones; que permite una descarga uniforme, a través de esclusas de tipo hidráulico, y en el que se logra la ausencia de pegaduras que, por su índole, era en los antiguos hornos un mal endémico, difícil de combatír.

- Ponencia presentada en los II Cologuios de Directores y Técnicos de Fabricas de Cemento. I. T. C. C., marzo de 1957 . 
El hecho es que, al tener un elemento más perfecto de calcinación, los crudos empleados tienen un grado de saturación en cal mayor $y$, en consecuencia, el clínker producido es más homogéneo en calidad, y ésta es francamente aceptable.

\section{CARBONES}

En estos hornos, y debido a que la clinkerización se realiza por convección $y$ en una zona corta, se necesitan carbones de gran poder calorifico y un foco de calefacción concentrada, para que todas las reacciones de combinación entre los elementos ácidos y básicos puedan realizarse lo más rápidamente posible.

De aquí el motivo de que se descarte totalmente el empleo de carbones ricos en volátiles, que dan lugar a la formación de dos zonas de clinkerización. Además, los gases que se desprenden en la combustión se evacuan por la chimenea, por to que son más apropiados estos carbones cuando la clinkerización se efectúe por radiación $y$ en una zona ancha.

Según esto, los carbones tipo para esta clase de hornos son: la antracita y el cok, o mezclas de éstos en la proporción de $70-30$, respectivamente.

Cuando se trabaja con antracita se observa una mayor facilidad en la combustión $\mathrm{y}$ el aspecto del horno es de mayor vivacidad, mientras que el foco de calefacción no resulta tan centralizado como cuando se quema cok solo.

Otro de los factores a considerar es la granulometría $y$, dado lo mucho que se ha comentado sobre el particular, creo conveniente dar a conocer las caracteristicas de nuestros carbones, no sólo por la aportación que pueda representar para este tema, sino también por el interés que siempre enclerra el disponer de mayor número de datos comparativos, para deducir de ellos las conclusiones pertinentes:

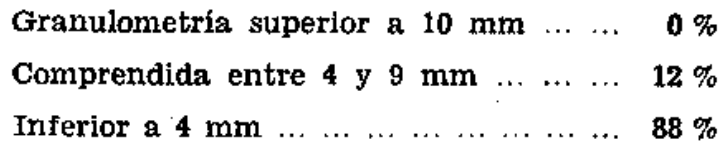

Como puede verse, differe mucho de la granulometría optima. Ahora blen, como estas determinaciones se han realizado previo secado del carbón, dicha granulometría no es fiel reflejo de la verdadera, ya que, debido a la humedad, se aglomerarán parte de los fnos, aumentando con ello el porcentaje comprandido entre 4 y $9 \mathrm{~mm}$.

\section{CRUDO}

Sin que suponga un menosprecio para la evolución experimentada por este tipo de hornos, los nuevos procedimientos de homogenelzación y molienda del crudo creo que han influído notablemente en cuanto al particular.

Quizás algunos no consideren de mucha importancia el preocuparse de la calidad del crudo, al ver que no pueden hacer lo mismo con el carbón. Esta forma de ver las cosas no deja de tener, en parte, su justiflcación; pero no hay duda de que, si tomamos todas las medidas precisas para consegulr una mayor constancia de todos aquellos factores que estén a nuestro alcance, tales como flnuras, dosiffcación de carbonatos y elementos arcillosos, evitaremos en gran parte las irregularidades que se nos puedan presentar posteriormente.

Digo que deben tomarse todas las medidas en cuanto a la regularidad del material crudo, dado que, al conseguirse una mayor homogeneidad del mismo, son patentes las ventajas que se logran en la marcha de los hornos rotativos: ahorro de calorias y uniformidad en la calldad del clínker. Si estas mejoras se han conseguido dentro de aquellos hornos en los que el hornero dispone de los medios necesarios para combatir y evitar la salida de un clinker de mala calidad, es lógico considerar que en otros hornos, Ios hornos verticales, en los que el hornero no puede intervenir para impedir la salida de un clínker de baja calcinación, una vez que el material esté dentro de ellos, todo aquello que contribuya a un riguroso y meticuloso control redundará en beneflcio del producto final.

El grado de flnura del crudo tiene suma importancia y, por ensayos realizados en fábrica, se ha comprobado que, mientras los residuos sean inferiores a 1 y $12 \%$ en los ta- 
mices de 900 y 4.900 mallas $/ \mathrm{cm}^{\prime}$, respectivamente, pueden realizarse perfectamente las reacciones; en cambio, con residuos más altos ya comienzan a observarse diffcultades.

Otro de Ios factores a considerar es el módulo de fundentes. Como se ha dicho anteriormente, la zona de clínkerización en estos hornos es corta y, con el fin de facilitar las reacciones, es conveniente la adición de cenizas de pirita, o fluoruro cálcico, siendo imprescindible esta última adición, sobre todo cuando se utiliza un material rico en sílice, con objeto de elevar el módulo silícico del crudo.

Hoy dia, y debido a las exigencias de los usuarios, los cementos deben desarrollar sus resistencias a corto plazo, es decir, deben ser de alto contenido en silicato trićlcico, lo que, referido al crudo, significa una alta dosificación en carbonato de cal, o, mejor dicho, un elevado grado de saturación.

Quizás el comentario que voy a hacer a continuación suscite muchas controversias; pero, sin pretender generalizar, y con el ánimo de aportar datos de experiencias realizadas, voy a decir algo acerca de la elaboración de un crudo con vistas a fabricar supercemento.

Prescindiendo de la clase de hornos, para dicha fabricación los crudos exigen, además de gran finura, un elevado grado de saturación. Ahora bien, en Ios hornos verticales, y debido a la incorporación de cenizas, se descorrige la dosiflcación, debiéndose tener en cuenta esta clrcunstancia en la preparación del material crudo. El trabajar con un elevado grado de saturaclón, implica una alta temperatura de clinkerización, lo que se refleja en un mayor consumo de carbón $\mathrm{y}$, como consecuencia, en un aumento de la incorporación de cenizas.

Las cenizas, aparte de sus caracteristicas y de su poder de combinación con la cal, dan lugar a un clinker de alto contenido en sillcato dicálcico, con la conslguiente disminución en silícato tricálcico.

Con esto no quiero descartar la posibilidad de fabricar supercementos, ya que, en el caso de que se pueda disponer de un buen carbón, asi como de un crudo de gran fusibilidad, creo factible la obtención de este típó de cemento.

A mi modo de ver, y para esta clase de hornos, creo conveniente trabajar con crudos un tanto ricos en silice, con vistas a la fabricación de cementos fríos o cementos portland corrientes.

\section{DOSIFICACION Y MEZCLA}

En la actualidad disponemos de dos básculas para cada horno-una para el carbón y otra para el crudo-, las cuales trabajan simultáneamente. La de carbón, y para mayor seguridad de trabajo, dada la humedad del material, tiene un dispositivo de alimentación a percusión.

Con este sistema, y con una buena homogeneización del crudo y una constancia en la humedad del carbón, previo almacenamiento del mismo en fábrica, se llega a conseguir unas dosiflcaciones, aunque no del todo exactas, si lo suficientemente prácticas.

Por tratarse de materiales distintos en sus características, así como en su granulometría, existía el temor de que no se pudiese lograr una buena mezcla de ellos; pero con las medidas preventivas adoptadas, tales como la descarga simultánea de los mismos en un elevador e instalación de una vis antes de la amasadora-mezcladora, se llega a conseguir una mezcla satisfactoria.

Para la adiclón de agua tenemos dos dispositivos: uno en el que el agua se añade en forma de chorro, y otro, con dos tubos horizontales, de distinta Iongitud, que distribuyen el agua en forma de lluvia. La diferencia en Ia longitud de dichos tubos tiene por objeto el que el material se pueda humedecer más en el tramo final, en el caso de que se observe que tiende a salir seco.

\section{MOLDEO}

En estos ultimos años existe la tendencia de dar al material una forma esférica, pero, bien por razones de orden económico, o porque los materiales no son aproplados, o por 
el deseo de disponer varios sistemas con el fln de poder realizar estudios comparativos, se observa, dentro de dicha tendencla, una actitud pasiva frente a la unfficación del sistema dentro de una misma fábrica.

La forma del materlal, a mi juiclo, no es tan influyente en la marcha del horno. Prueba de ello es que, trabajando con un mismo material, pero con distinta forma, no se observan grandes diferencias en cuanto al paso de los gases. En cambio, se debe prestar especial atención al tamaño y la porosidad.

Respecto de la formación de nódulos, tiene suma importancia la plasticidad del crudo, siendo ésta la que contribuye al éxito de una buena granulación. La mayor o menor plasticidad del material crudo depende de las caxacteristicas de las materias primas, así como de las dosificaciones que se realicen con las mismas. En nuestro caso, como la marga que empleamos es muy plástica y entra en la preparación del crudo en una proporción considerable, hace que éste sea muy apropiado para la granulación.

Ante las eventuales irregularidades en la distribución del carbón, debido a su elevado contenido en flnos, se han efectuado diversos ensayos con las distintas fracciones granulométricas de los nódulos para comprobar la posible heterogeneidad. Por los resultados obtentdos se ha llegado a la conclusión de que, tanto en los tamaños superiores a $18 \mathrm{~mm}$ como en los comprendidos entre 4 y $9 \mathrm{~mm}$ y en los inferlores a $4 \mathrm{~mm}$, independientemente de la forma esférica o no del gránulo, la proporción crudo-carbón es igual en todos ellos, lo cual confirma la eflcacla de Ia mezcla, así como la regularidad en la distribución del carbón.

\section{CLINKERIZACION}

Así como en los hornos rotativos se pueden distinguir todas Ias zonas, en los verticales resulta francamente imposible diferenciar la zona de descarbonatación de la de clinkerización.

Debido a los inyectores, hoy día se puede decir que no existe problema de clinkerizactón, considerado desde el punto de vista de la combustión. En camblo, en otros aspectos continua siendo un verdadero problema, por los innumerables factores que intervienen en la misma.

Como quiera que dichos factores, como son la distribución del material y de los fuegos, apelmazamientos, etc., son más bien de orden práctico que técnico, he creído oportuno no hacer comentarlo alguno acerca de cllos, por ser de todos conocidos. No obstante, voy a detallarles una anormalidad presentada en uno de los dos hornos de que disponemos.

Colncidía ésta con la puesta en marcha de dicho horno, después de haber efectuado varias modiflcaciones, tales como el ensanchamiento de la zona de clinkerización, la sustitución del ventilador por un inyector a presión y el cambto de esclusas mecónicas por otras hidráulicas.

Como se flgurarán, existia verdadero interés por ver su funcionamiento, $y$, en honor a la verdad, he de decirles que todo marchaba perfectamente, hästa que, un buen dia, sin haber efectuado ningún cambio en el crudo nl en el carbón, asi como tampoco en la presión y caudal del aire; se observó una zona muerta debajo de la chimenea, que se extendia a lo largo de la misma, mientras que en el resto del horno la distribución de los fuegos era perfecta.

Pensando que no hublese fuego en la referida zona, se bajó la clinkerización hasta una altura determinada, para luego subirla de nuevo, pero no se logró el resultado que pretendíamos. Entonces se creyó fuera debido a un mal encendido $y$, con el fin de descartar esta posibilldad, se dejó apagar el horno, para efectuar nuevamente su encendido. Cuál no seria nuestro asombro cuando, a los pocos días, surgió nuevamente la zona muerta y en el mismo sitio. .

Como comprenderán, el fenómeno no dejaba de ser interesante; pero dentro de los innumerables que diarlamente se presentan, más que un problema interesante venía a ser una pesadilla. Afortunadamente, con una pequeña 
reforma efectuada en la chimenea se logró desapareclese aquélla. No obstante, si surge una irregularidad o debilidad dentro del horno tiende siempre a presentarse nuevamente por el mismo sitio.

\section{REFRACTARIOS}

Si la formación de anillos en los hornos rotativos sigue slendo un problema en la actualidad, en los hornos verticales puede decirse que no existe tal problema.

Según la opinión de algunos autores, el origen de las pegaduras, más que al contacto de las cenizas del carbón con el refractario, es debido a la reacción entre el clínker y el revestimiento, no teniendo influencia alguna la combustión.

Salvo en clertos casos de concentración de fuegos o de enfriamientos ocasionados al tra- bajar con una alta dosiffcación en cal, es muy rara la formación de pegaduras.

Normalmente, en estos hornos, y para la zona de clinkerización, se emplean refractarios aluminosos, extraaluminosos y de magnesita, mientras que en el resto del horno se emplean otros de inferior calldad. En Ia parte baja del horno, y debido a su gran desgaste, se aconseja la colocación de unos refuerzos 0 corazas que eviten el contacto entre el clinker $y$ el refractario.

En cuanto a la calldad del refractario a emplear en la zona de clinkerización, cualquiera de los tres anteriormente cltados da buen resultado, aunque aIgunos aconsejan el empleo de la magnesita, debido a su carácter básico, eliminando con ello toda posible formación de pegaduras. En nuestro caso, y empleando un refractario aluminoso, no hemos tenido problema alguno con el revestimiento, slendo su duración media de cuatro a cinco años. 